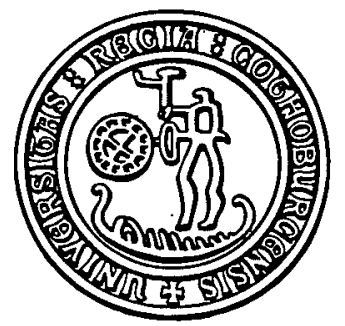

Research Report

Department of Statistics

Göteborg University

Sweden

\title{
The causal nexus of government spending and revenue in Finland: \\ A bootstrap approach
}

\section{Abdulnasser Hatemi-J \\ Ghazi Shukur}

Research Report 1998:10

ISSN 0349-8034

Mailing address:

Department of Statistics

Göteborg University

Box 660

SE 40530 Göteborg

Sweden
Home Page:

Phone

Nat: 031-773 $1000 \quad$ http://www.stat.gu.se

Nat: 031-773 1274

Int: +46317731274

Int: +46317731000 
* To appear in Applied Economics Letters, 1999.

\title{
THE CAUSAL NEXUS OF GOVERNMENT SPENDING AND REVENUE IN FINLAND: \\ A BOOTSTRAP APPROACH
}

\author{
Abdulnasser Hatemi-J and Ghazi Shukur \\ Department of Economics, Lund University and \\ Department of Statistics, Göteborg University, \\ Sweden
}

\begin{abstract}
Applying VAR(5), a bootstrap simulation approach and a multivariate Rao's $F$-test indicate that government revenue Granger causes spending in Finland. This does not agree with Barro's tax smoothing hypothesis. The explanation of this is due to the institutional factors that are specific for Finland.
\end{abstract}

Keywords: Bootstrap, Government Spending and Revenue, Granger Causality, VAR.

JEL Classification: C32, H00 


\section{INTODUCTION}

In the vector autoregressive (VAR) framework, the Wald test for testing the Granger-causality may have non-standard asymptotic properties if the variables considered in the VAR are integrated or cointegrated. However, Dolado and Lütkepohl (1996), in what follows referred to as DL, proposed a solution that guarantees standard $\chi^{2}$ asymptotic distribution for the Wald tests performed on the coefficients of cointegrated VAR processes with I(1) variables if at least one coefficient matrix is unrestricted under the null hypothesis. Similarly, if all the matrices are restricted, it is shown that adding one extra lag to the process and concentrating on the original set of coefficients result in Wald tests with standard asymptotic distributions. This result of course, leads to a number of interesting implications which stem from the possibility of expressing null hypotheses as restrictions on coefficients of stationary variables.

Shukur and Mantalos (1998), in what follows referred to as SM, have considered the size and power of various generalisations of tests for Granger-causality in integrated-cointegrated VAR systems. The authors used Monte Carlo methods to investigate the properties of eight versions of the test in two different forms, the standard form and the modified form by DL. In both studies, the standard and the modified Wald tests have shown to perform badly, especially in small samples. In the SM study, however, the authors found that the small-sample corrected LR-tests, and especially the Rao's multivariate $F$-test, exhibit best performances regarding both size and power, even in small samples. In the case when we use the standard test and when there is no cointegration, however, all the tests have shown to perform poorly, especially in small samples. Mantalos (1998), in what follows referred to as M, studied the properties of Wald, corrected-LR and Bootstrap tests for the same purpose. The author showed that, even when the non-stationary variables are not cointegrated, the Bootstrap test exhibits the best performance in almost all situations.

The purpose of this paper is to apply these methods to test for the causal nexus of government spending and revenue in Finland. That is to say, we intend to investigate whether the political system first decide how much to spend and then decide how much to bring in as revenue by taxes, or if it is the other way around, or are the decisions simultaneous. 
Shukur and Hatemi-J (1998), in what follows referred to as SH-J, investigated this subject and tried to analytically answer some questions regarding government financial policy in Finland. The authors used an VAR model and an VECM in their study, and found that government revenue Granger causes spending for the sample period 1960:1 to 1997:2.

In this paper, in addition to singlewise (LR) tests for causality, we will use the two recommended, Rao's $F$-test and the Bootstrap test mentioned in SM and M. In the next section we present data and model specification. In Section 3, we describe the systemwise Rao's test for Granger causality. In Section 4, we present the Bootstrap testing approach. while in section 5, we show our test results and compare them with those found by SH-J. Finally, in Section 6, we give a brief summary and conclusions.

\section{DATA AND MODEL SPECIFICATION}

The investigation of the causal relationship between government spending $(S)$ and government revenue $(R)$ is performed by using quarterly data on these two macro variables. The data are drawn from the International Monetary Found (IMF), and cover the period 1960:1 through 1997:2.

SH-J test for causality in Granger sense by means of the following vector autoregressive (VAR) model:

$$
\begin{aligned}
& \ln R_{t}=a_{0}+\sum_{i=1}^{k} a_{i} \ln R_{t-i}+\sum_{i=1}^{k} b_{i} \ln S_{t-i}+e_{1 t}, \\
& \ln S_{t}=c_{0}+\sum_{i=1}^{k} c_{i} \ln R_{t-i}+\sum_{i=1}^{k} f_{i} \ln S_{t-i}+e_{2 t},
\end{aligned}
$$

where $e_{1 t}$ and $e_{2 t}$ are innovations, which are assumed to be white noise with zero mean, constant variance and no autocorrelation. The number of lags, $k$, has been decided to be equal to five by using the Schwarz (1978) information criteria, the Hannan and Quinn (1971) criteria and the systemwise likelihood ratio (LR) test. The decision of choosing the VAR(5) model has also been supported by a battery of singlewise and systemwise diagnostic tests. 
SM-J have also tested Granger causality by using a vector error correction model (VECM), that is:

$$
\begin{aligned}
& \Delta \ln \mathrm{R}_{\mathrm{t}}=\mathrm{g}_{0}+\mathrm{g}_{1} \mathrm{z}_{\mathrm{t}-\mathrm{l}}+\sum_{\mathrm{i}=1}^{\mathrm{k}} \mathrm{h}_{\mathrm{i}} \Delta \ln \mathrm{R}_{\mathrm{t}-\mathrm{i}}+\sum_{\mathrm{i}=1}^{\mathrm{k}} \mathrm{j}_{\mathrm{i}} \Delta \ln \mathrm{S}_{\mathrm{t}-\mathrm{i}}+\mathrm{w}_{1 \mathrm{t}}, \\
& \Delta \ln \mathrm{S}_{\mathrm{t}}=\mathrm{g}_{0}+\mathrm{g}_{1} \mathrm{z}_{\mathrm{t}-1}+\sum_{\mathrm{i}=1}^{\mathrm{k}} \mathrm{h}_{\mathrm{i}} \Delta \ln \mathrm{R}_{\mathrm{t}-\mathrm{i}}+\sum_{\mathrm{i}=1}^{\mathrm{k}} \mathrm{j}_{\mathrm{i}} \Delta \ln \mathrm{S}_{\mathrm{t}-\mathrm{i}}+\mathrm{w}_{1 \mathrm{t}},
\end{aligned}
$$

where $w_{1 t}$ and $w_{2 t}$ are new innovations, which are assumed to be white noise with zero mean, constant variance and no autocorrelation. $\Delta$ denotes the first difference. The variable $z_{t-1}$ is the residuals from a regression of $\ln R$ on $\ln S$. If the coefficient of $\mathrm{z}_{\mathrm{t}-1}$ is significantly different from zero then the variables are cointegrated. According to Granger (1988), the presence of cointegration implies Granger causality in at least one direction between the variables involved. If the values of $j_{i}$ are jointly zero for all $i$, or if $g_{l}$ is non-significant, then the hypothesis that $\ln S$ does not Granger cause $\ln R$ can not be rejected.

We, however, use the same VAR(5) model as in the SH-J for the purpose of testing for Granger causality by using the Rao's $F$-test and the Bootstrap test.

\section{THE SYSTEMWISE RAO'S F-TEST}

In this section we present the SM version of the Granger-causality test by using the multivariate Rao's F-test (Rao, 1973). Consider the following VAR(p) process:

$$
y_{t}=\eta+A_{1} y_{t-1}+\ldots+A_{p} y_{t-p}+\varepsilon_{t}
$$

where $\varepsilon_{t}=\left(\varepsilon_{l t}, \ldots, \varepsilon_{k t}\right)^{\prime}$ is a zero mean independent white noise process with nonsigular covariance matrix $\Sigma_{\varepsilon}$ and, for $\mathrm{j}=1, \ldots, \mathrm{k}, \mathrm{E}\left|\varepsilon_{j t}\right|^{2+\tau}<\infty$ for some $\tau>0$. The order $\mathrm{p}$ of the process is assumed to be known. Now, by portioned $y_{t}$ in $(\mathrm{m})$ and $(\mathrm{k}-\mathrm{m})$ dimensional subvectors $y_{t}^{1}$ and $y_{t}^{2}$ and $A_{i}$ matrices portioned comfortably then $y_{t}^{2}$ does not Grangercause the $y_{t}^{1}$ if the following hypothesis: 


$$
H_{0}=\mathrm{A}_{12, \mathrm{i}}=0 \text { for } \mathrm{i}=1, \cdots, p-1
$$

is true.

Let us define:

$\mathrm{Y}:=\left(\mathrm{y}_{1}, \cdots, \mathrm{y}_{\mathrm{T}}\right) \quad(\mathrm{k} \times \mathrm{T})$ matrix

$\mathrm{B}:=\left(\mathrm{v}, \mathrm{A}_{1}, \cdots, \mathrm{A}_{\mathrm{p}}\right)(\mathrm{k} \times(\mathrm{kp}+1))$ matrix,

$\mathrm{Z}_{\mathrm{t}}:=\left[\begin{array}{c}1 \\ \mathrm{y}_{\mathrm{t}} \\ \vdots \\ \mathrm{y}_{\mathrm{t}-\mathrm{p}+1}\end{array}\right]((\mathrm{kp}+1) \times 1)$ matrix

$\mathrm{Z}:=\left(\mathrm{Z}_{0}, \cdots, \mathrm{Z}_{\mathrm{T}-1}\right) \quad((\mathrm{kp}+1) \times \mathrm{T})$ matrix, and

$\delta:=\left(\varepsilon_{1}, \cdots, \varepsilon_{\mathrm{T}}\right) \quad(\mathrm{k} \times \mathrm{T})$ matrix.

By using these notations, for $t=1, \ldots, T$, the VAR (p) model including a constant term $(v)$ can be written compactly as:

$$
\mathrm{Y}=\mathrm{BZ}+\delta .
$$

Then the LS estimator of the B is:

$$
\widehat{\mathrm{B}}=\mathrm{YZ}\left(\mathrm{ZZ} \mathrm{Z}^{\prime}\right)^{-1}
$$

Let us denote by $\widehat{\delta}_{\mathrm{U}}$ the $(k \times T)$ matrix of estimated residuals from the unrestricted regression (7) and by $\widehat{\delta}_{\mathrm{R}}$ the equivalent matrix of residuals from the restricted regression with $H_{0}^{\prime}$ imposed. The matrix of cross-products of these residuals will be defined as $S_{U}=\widehat{\delta}_{U}{ }^{\prime} \widehat{\delta}_{U}$ and $S_{R}=\widehat{\delta}_{R}, \widehat{\delta}_{R}$ respectively. The Rao test can be then written as:

$$
R A O=(\phi / q)\left(U^{1 / s}-1\right)
$$

where $\phi=\Delta \mathrm{s}-\mathrm{r}, \Delta=\mathrm{T}-(\mathrm{k}(\mathrm{kp}+1)-\mathrm{Gm})+1 / 2[\mathrm{k}(\mathrm{G}-1)-1], r=q / 2-1, U=\operatorname{det} \mathbf{S}_{R} / \operatorname{det} \mathbf{S}_{U}$. $q=G m^{2}$ is the number of restrictions imposed by $H_{0}$, where $\mathrm{G}$ is the $p$ restriction in (7) and $\mathrm{m}$ is the dimension of the subvector $y_{t}^{1}$.

$$
s=\sqrt{\frac{q^{2}-4}{k^{2}\left(G^{2}+1\right)-5}} .
$$


$R A O$ is approximately distributed as $F(q, \phi)$ under the null hypothesis, and reduces to the standard $F$ statistic when $k=1$.

\section{THE BOOTSTRAP TESTING APPROACH}

In this section we present the Bootstrap testing procedure (Efron, 1979). Generally, the distributions of the test statistics we use are known only asymptotically, which means that the tests may not have the correct size, and inferential comparisons and judgements based on them could be misleading. However, several studies (e.g. Horowitz, 1994; Mantalos and Shukur, 1998; and Shukur and Mantalos, 1997), have shown the robustness of the bootstrap critical values.

From regression (7), a direct residual resampling gives:

$$
\mathrm{Y}^{*}=\widehat{\mathrm{B}} \mathrm{Z}^{*}+\delta^{*}
$$

where $\delta^{*}$ are i.i.d observations $\delta_{1}{ }^{*}, \ldots, \delta_{\mathrm{T}}{ }^{*}$, drawn from the empirical distributions $\left(\widehat{\mathrm{F}}_{\delta}\right)$ putting mass $1 / \mathrm{T}$ to the adjusted OLS residuals $\left(\widehat{\delta}_{i}-\bar{\delta}\right), i=1, \ldots, T$. The basic principle of the Bootstrap testing is to draw a number of Bootstrap samples from the model under the null hypothesis, calculate the Bootstrap test statistic $\left(T_{s}^{*}\right)$. The Bootstrap test statistic $\left(T_{s}^{*}\right)$ can then be calculated by repeating this step $\mathrm{N}_{\mathrm{b}}$ number of times. We then take the $(\alpha)$ :th quintile of the bootstrap distribution of $T_{s}^{*}$ and obtain the $\alpha$-level "bootstrap critical values" $\left(c_{t \alpha}^{*}\right)$. We then calculate the test statistic $\left(\mathrm{T}_{s}\right)$ which is the estimated test statistic, as described in Section 3 , using the actual data set. Finally, we reject the null hypothesis if $\mathrm{T}_{s} \leq c_{t \alpha}^{*}$.

As regards $\mathrm{N}_{b}$, the number of the bootstrap samples used to estimate bootstrap critical value, Horowitz (1994) used the value of $\mathrm{N}_{\mathrm{b}}=100$, while Davidson and Mckinnon (1996) used $\mathrm{N}_{\mathrm{b}}=1000$ to estimate the P-value. In this study we estimate the P-value for the test using $\mathrm{N}_{\mathrm{b}}=1000$. 


\section{RESULTS}

Using the same VAR(5) model as in the SH-J, we present here the results of the Rao's $F$-test and the Bootstrap test. These results will be compared with those found by the SH-J to see if the conclusions will hold regarding the causal nexus of government spending and revenue in Finland.

When we test the VAR(5) model for causality, all the test methods lead us to draw the inference that only $\ln R E V$ Granger causes $\ln S P E N$. This means that the causality nexus in Finland has a one-directional form, i.e., from $\ln R E V$ to $\ln S P E N$, which in turn implies that the political system in Finland decides first how much to bring in by taxes as revenue and thereafter decides how much to spend. In other words, the decisions regarding the amount of revenue in Finland during the period 1960 through 1997, precede the decisions about the amount of spending. The results for these tests can be found in the following table.

Different test results for causality in the Granger sense, applying VAR(5).

\begin{tabular}{|c|c|l|c|}
\hline Null Hypothesis & & P-values & \\
\cline { 2 - 4 } & Bootstrap test & Rao's $F$-test & LR singlewise \\
\hline $\begin{array}{c}\text { InSPEN does not } \\
\text { Granger Cause lnREV }\end{array}$ & 0.420 & 0.357 & 0.355 \\
\hline $\begin{array}{c}\text { InREV does not Granger } \\
\text { Cause lnSPEN }\end{array}$ & 0.000 & 0.016 & 0.016 \\
\hline
\end{tabular}

The estimated results for Granger causality, applying the chosen VECM(5) in the SH-J study, also indicate the same results.

\section{SUMMARY AND CONCLUSIONS}

In this study, we investigate the causal nexus of government spending and revenue in Finland during the period of 1960:1 to 1997:2. We use both multivariate Rao's F-test and Bootstrap test applied to VAR(5). This model has been applied earlier by SH-J, among other things, to test for the same purpose. The results from our study are shown to be similar to those found 
by SH-J. These results indicate that only $\ln R E V$ Granger causes $\operatorname{lnSPEN}$. This means that the decisions regarding the amount of revenue in Finland precede the decisions regarding the amount of spending. Based on the estimated results, we can conclude that government revenue Granger causes spending for the entire period.

It should be important to mention that the estimated causality result for Finland does not accord with Barro's (1979) tax smoothing hypothesis, which assumes that causality runs from government spending to revenue. Our conjecture is that this might be due to the institutional factors that are specific for Finland. More explicitly, the decisions regarding the amount of taxes requires a majority of seventy five percent of votes in the Finnish parliament, while forming a new government in Finland requires only a majority of more than fifty percent. This might be the explanation of the fact that the government has to adjust the amount of spending to the amount of taxes in Finland.

\section{REFERENCES}

Barro, R. L. (1979): "On the determination of the public debt" Journal of political economy, 87, 940941.

Granger, C. W. J. (1969): "Investigating Causal Relations by Econometric Models an Cross-Spectral Methods," Econometrica, 37, 24-36.

Davidson, R and J.G. MacKinnon (1996): "The size Distortion of Bootstrap Tests" Working Paper, Department of Economics, University of Queen's, Canada.

Dolado, J. J. and Lutkepohl, H. (1996): "Making Wald Tests Work for Cointegrated VAR Systems," Econometrics Reviews 15, 369-386.

Efron, B. (1979):"Bootstrap methods: Another look at the jackknife," Annals of Statistics 7, 1-26.

Hannan, E. J., and Quinn, B.G. (1979): "The Determination of the Order of an Autoregressive," Journal of the Royal Statistical Society, B41, 190-195.

Horowitz, J. L. (1994): "Bootstrap-based critical values for the information matrix test," Journal of Econometric, 61, 395-411. 
Mantalos, P. (1998): "A Graphical Investigation of the Size and Power of the Granger-Causality Tests in Integrated-Cointegrated VAR Systems," Working paper 1998:2, Department of Statistics, Lunds University, Sweden.

Mantalos, P. and Shukur, G. (1998): "Size and Power of the Error Correction Model Cointegration Test. A Bootstrap Approach," Oxford Bulletin of Economics and Statistics, 60, 249-255.

Rao, C. R. (1973): "Linear Statistical Inference and Its Application," Second edition. New York: Wiley.

Schwarz, G. (1978): "Estimation the Dimension of a Model," Annals of Statistics, 6, 461-464.

Shukur, G. and Hatemi-J A. (1998): "The Causal Nexus of Government Spending and Revenue in Finland," Working paper 1998:3, Department of Statistics and Department of Economics, Lunds University, Sweden.

Shukur, G., and P. Mantalos (1997): "Size and Power of the RESET Test as Applied to Systems of Equations : A Bootstrap Approach," Department of Statistics, Working paper 1997:3, Lunds University, Sweden.

Shukur, G. and Mantalos, P. (1998): " Testing for the Granger Causality in Integrated-Cointegrated VAR Systems," Working paper 1998:1, Department of Statistics, Lunds University, Sweden. 